\title{
Empagliflozin. Results of the EMPA-REG OUTCOME trial. A breakthrough in treatment of type 2 diabetes?
}

\section{ABSTRACT}

Cardiovascular (CV) complications are the main health challenge among type 2 diabetic patients. They may cause premature death, disability and reduce the quality of life. Administering a multifactorial intervention aimed at controlling glycaemia, lipaemia and arterial blood pressure allows to reduce the risk of their occurrence. FDA ruled that all newly introduced hypoglycaemic agents must undergo tests for CV safety. The EMPAREG OUTCOME trial was conducted on a group of type 2 diabetic patients at high CV risk. It showed that including empagliflozin in the standard therapy reduces the risk of primary outcome (death from CV causes, non-fatal myocardial infarction or non-fatal stroke) by $14 \%$ and all-cause mortality by $32 \%$. The causes of this effect of empagliflozin - an inhibitor of SGLT2, which is an enzyme present only in renal proximal tubules - are unclear. Reduction in insulin resistance and in oxidative stress, changes in lipid levels, reduction in uric acid levels, in albuminuria, in blood pressure and reduction in sympathetic activity are all named as potential mechanisms underlying the protective effect of empagliflozin.

Results of the EMPA-REG OUTCOME trial are a breakthrough in the treatment of diabetes, and if other SGLT2 inhibitors are found to have similar effects, a fundamental change in therapy recommendations

Address for correspondence:

prof. dr hab. n. med. Krzysztof Strojek

Oddział Kliniczny Chorób Wewnętrznych, Diabetologii i Schorzeń

Kardiometabolicznych w Zabrzu

ul. Marii Curie-Skłodowskiej 9, 41-800 Zabrze

e-mail: kstrojek@sum.edu.pl

Translation: GROY Translations

Clinical Diabetology 2016, 5, 3, 107-110

DOI: $10.5603 /$ DK.2016.0018

Received: 03.08.2016

Accepted: 07.08.2016 for this patient population may be made. (Clin Diabet 2016; 5, 3: 107-110)

Key words: diabetes type 2, cardiovascular complications, SGLT2 inhibitors, EMPA-REG OUTCOME

\section{Introduction}

Cardiovascular (CV) complications are the main health problem among type 2 diabetic patients [1]. In this patient population, a concomitant CV disease multiplies the risk of premature death [2]. A multifactorial therapy, encompassing simultaneous normalization of glycaemia, lipaemia and arterial blood pressure, allows to reduce this risk [3]. Data concerning the effect of glycaemia normalization on CV complications is inconsistent. On one hand, an intervention aimed at reducing CV risk showed no effects [4-6]. On the other hand, however, such preventive effect of glycaemia normalization was documented during a prolonged, 20-year-long observation [7]. The effect of individual hypoglycaemic agents on CV safety is a separate issue [8]. Due to these doubts, U.S. Food and Drug Administration (FDA) ruled that all newly introduced hypoglycaemic agents are required to undergo tests for CV safety [9].

Flozins - sodium-glucose linked transporter 2 (SGLT2) inhibitors - are the newest class of hypoglycaemic agents. Their mechanism of action is based on blocking glucose reabsorption from the renal ultrafiltrate and therefore inducing glycosuria [10]. Clinical effect of using SGLT2 inhibitors, apart from a reduction in $\mathrm{HbA} 1 \mathrm{c}$ levels, manifests itself as loss of body weight and a slight decrease in systolic arterial blood pressure [11]. At the same time, using this class of drugs causes an increase in the levels of HDL and LDL cholesterol fractions, as well as adverse effects, such as urinary tract and genitourinary infections [12]. 
Table 1. The EMPA-REG OUTCOME trial. Baseline characteristics of subjects - metabolic condition

\begin{tabular}{lccc}
\hline & $\begin{array}{c}\text { Placebo } \\
(\mathbf{n}=\mathbf{2 3 3 3})\end{array}$ & $\begin{array}{c}\text { Empagliflozin } \\
10 \mathbf{~ m g} \\
(\mathbf{n}=\mathbf{2 3 4 5})\end{array}$ & $\begin{array}{c}\text { Empagliflozin } \\
\mathbf{2 5} \mathbf{~ m g ~} \\
(\mathbf{n}=\mathbf{2 3 4 2})\end{array}$ \\
\hline $\mathrm{HbA}_{1 \mathrm{c}}(\%)$ & & 8.07 & 8.06 \\
$\mathrm{BMI}\left[\mathrm{kg} / \mathrm{m}^{2}\right]$ & 8.08 & 30.6 & 30.6 \\
Duration of diabetes $\leq 5$ years [n (\%)] & 30.7 & $406(17.3)$ & $434(18.6)$ \\
Duration of diabetes 5-10 years [n (\%)] & $423(18.1)$ & $585(24.9)$ & $590(25.2)$ \\
Duration of diabetes $>10$ years [n (\%)] & $571(24.5)$ & $1354(57.7)$ & $1318(56.3)$ \\
Systolic BP $[\mathrm{mm} \mathrm{Hg}]$ & $1339(57.4)$ & 134.9 & 135.6 \\
Diastolic BP $[\mathrm{mm} \mathrm{Hg}]$ & 135.8 & 76.6 & 76.6 \\
LDL $[\mathrm{mg} / \mathrm{dL}]$ & 76.8 & 86.3 & 85.5 \\
\hline
\end{tabular}

Table 2. The EMPA-REG OUTCOME trial. Baseline characteristics of subjects - presence of cardiovascular disorders

\begin{tabular}{lccc}
\hline & $\begin{array}{c}\text { Placebo } \\
(\mathbf{n}=\mathbf{2 3 3 3})\end{array}$ & $\begin{array}{c}\text { Empagliflozin } \\
\mathbf{1 0} \mathbf{~ m g} \\
(\mathbf{n}=\mathbf{2 3 4 5})\end{array}$ & $\begin{array}{c}\text { Empagliflozin } \\
\mathbf{2 5} \mathbf{~ m g} \\
(\mathbf{n}=\mathbf{2 3 4 2})\end{array}$ \\
\hline Presence of CV risk factors & $2307(98.9 \%)$ & $2333(99.5 \%)$ & $2324(99.2 \%)$ \\
Coronary artery disease & $1763(75.6 \%)$ & $1782(76.0 \%)$ & $1763(75.3 \%)$ \\
Multivessel coronary artery disease & $1100(47.1 \%)$ & $1078(46.0 \%)$ & $1101(47.0 \%)$ \\
Prior myocardial infarction & $1083(46.4 \%)$ & $1107(47.2 \%)$ & $1083(46.2 \%)$ \\
CABG & $563(24.1 \%)$ & $594(25.3 \%)$ & $581(24.8 \%)$ \\
Peripheral artery disease & $479(20.5 \%)$ & $465(19.8 \%)$ & $517(22.1 \%)$ \\
Prior stroke & $553(23.7 \%)$ & $535(22.8 \%)$ & $549(23.4 \%)$ \\
Heart failure & $244(10.5 \%)$ & $240(10.2 \%)$ & $222(9.5 \%)$ \\
\hline
\end{tabular}

Empagliflozin is one of the most recently introduced drugs belonging to this class. Its clinical effects have been confirmed in multiple clinical trials [13-15]. The EMPA-REG OUTCOME trial was performed in order to assess CV morbidity and mortality in patients with type 2 diabetes at high CV risk. Its results were presented during the European Association for the Study of Diabetes Meeting in September 2015 and simultaneously published [16].

\section{The EMPA-REG OUTCOME trial}

Over 7 thousand patients with type 2 diabetes and a CV disease took part in the trial (Table 1 and 2). Exclusion criteria included patients with $\mathrm{BMI}$ above $45 \mathrm{~kg} / \mathrm{m}^{2}$, GFR below $30 \mathrm{~mL} / \mathrm{min} / 1.73 \mathrm{~m}^{2}$ or $\mathrm{HbA}_{1 \mathrm{c}}$ levels outside of $7-10 \%$ range. All patients were administered unchanged hypoglycaemic therapy during 12 weeks preceding randomization.

After the initial period, patients were randomly divided (randomized) into groups receiving either empagliflozin at a dose of 10 or $25 \mathrm{mg}$ or placebo in a 1:1:1 ratio. The drugs were added to the current hypoglycaemic therapy. During the trial, investigators were encouraged to adjust treatment of other CV risk factors, including hypertension and dyslipidemia.

The following were assessed during the trial:

- occurrence of a primary outcome - death from CV causes, non-fatal myocardial infarction (excluding silent myocardial infarction) or non-fatal stroke;

- secondary outcome additionally included hospitalization for unstable angina;

- furthermore, changes in the following parameters compared to baseline values were analysed: $\mathrm{HbA}_{1 \mathrm{c}}$ levels, weight, WHR, blood pressure, heart rate, LDL and HDL cholesterol levels and uric acid levels.

\section{Results}

A significant reduction in the risk of all analysed outcomes was noticed in case of patients treated using empagliflozin (Table 3 ). This significant reduction was similar for both patients receiving $10 \mathrm{mg}$ dose of empagliflozin and patients receiving $25 \mathrm{mg}$ dose of empagliflozin. After 12 weeks of therapy, reduction in $\mathrm{HbA}_{1 \mathrm{c}}$ levels achieved in the groups treated using empagliflozin was different compared to reduction in $\mathrm{HbA}_{1 \mathrm{c}}$ levels achieved in the placebo group, by $0.54 \%$ 
Table 3. The EMPA-REG OUTCOME trial - results

\begin{tabular}{lcc}
\hline Parameter & HR $(\mathrm{Cl})$ & $\mathrm{P}$ \\
\hline Primary outcome & $0.86(0.74-0.99)$ & $\mathrm{P}=0.04$ \\
Secondary outcome & $0.89(0.78-1.01)$ & $\mathrm{P}=0.08$ \\
CV death & $0.62(0.49-0.77)$ & $\mathrm{P}<0.001$ \\
All cause death & $0.68(0.57-0.72)$ & $\mathrm{P}<0.001$ \\
Hospitalization for heart failure & $0.65(0.50-0.85)$ & $\mathrm{P}=0.002$ \\
\hline
\end{tabular}

(10 mg dose) and 0.6\% (25 mg dose). After 206 weeks of therapy these differences were lower: $0.24 \%$ (10 mg dose) and $0.36 \%$ (25 mg dose). Frequency of hypoglycaemic events was similar in all groups; respectively, they affected $27.9 \%$ of patients in the placebo group, $28 \%$ of patients in the $10 \mathrm{mg}$ empagliflozin group and $27.6 \%$ of patients in the $25 \mathrm{mg}$ empagliflozin group. Severe hypoglycaemic events occurred in $1.5 \%$ of patients receiving placebo, $1.4 \%$ of patients receiving $10 \mathrm{mg}$ empagliflozin and $1.3 \%$ of patients receiving $25 \mathrm{mg}$ empagliflozin. A slight reduction in body weight, uricemia, blood pressure and a slight increase in the levels of HDL and LDL cholesterol fractions were noted in patients treated using empagliflozin compared to values observed during the placebo therapy. Analysing the frequency of adverse events, the authors of the trial found that genital infections affecting both sexes were significantly more common in groups receiving empagliflozin $(6.4 \%$ vs. $1.8 \%)$, while patients in the group treated using placebo were found to develop acute renal failure significantly more often (6.6\% vs. $5.2 \%)$; significantly more frequent urinary tract infections in female patients in the placebo group were also observed (40.6\% vs. 36.4\%). Frequency of diabetic ketoacidosis did not exceed $0.1 \%$ and was similar in all groups.

In conclusion of their work the authors state that adding empagliflozin to current hypoglycaemic therapy reduces mortality due to cardiovascular causes and other causes in patients with type 2 diabetes with concomitant cardiovascular disease.

\section{Commentary}

The results of the EMPA-REG OUTCOME have shown that including empagliflozin in the standard treatment of patients with type 2 diabetes at high cardiovascular risk allows for a statistically significant $38 \%$ reduction in the number of deaths due to cardiovascular causes. Empagliflozin is the first hypoglycaemic agent for which a protective effect against death was observed. Using the drug allows to save the life of 1 patient per 39 treated (NNT — number needed to treat). Beneficial effect of empagliflozin occurred irrespectively of how well glycaemia was controlled. Despite the fact that the protocol of the trial allowed for intensification of hypoglycaemic therapy, $\mathrm{HbA}_{1 \mathrm{c}}$ levels at the end of the observation were 8.16 in the placebo group and 7.81 in the group treated using empagliflozin. This indicates that whether glycaemia is controlled or not is of less significance for achieved results. On the other hand, this also confirms that postulating more lenient criteria for glycaemia control in patients with CV diseases is valid [17]. The beneficial protective effect of empagliflozin was already visible after only a few months of treatment, which means that it is highly difficult to point out the exact mechanism which causes the action protecting against premature death, especially since no significant reduction in the risk of myocardial infarction or non-fatal stroke has been observed. This may be due to the cardiological profile of patients, since in this case adequate hypotension (more than $80 \%$ were taking drugs which block the RAAS) and hypolipidemic ( $75 \%$ were taking statin) therapies were being administered; $80 \%$ of patients were also taking aspirin. This confirms a direct effect of empagliflozin, supporting optimal cardiological treatment, on mortality. The actual mechanism of this protective action remains an open question.

The following mechanisms are postulated [18]:

- reduction in insulin resistance;

- reduction in oxidative stress;

- increase in levels of HDL cholesterol fractions and reduction in levels of triglycerides despite an increase in LDL cholesterol levels;

- reduction in uric acid levels;

- reduction in albuminuria;

- reduction in systolic blood pressure and arterial stiffness:

- reduction in sympathetic activity.

This kind of influence of SGLT2 inhibitors as an added effect to other clinical features, namely reduction in glycaemia and body mass, was documented in numerous clinical and experimental trials [18].

Another interesting hypothesis explaining the cardioprotective effect of empagliflozin was presented by Ferranini et al. [19]. They postulate that under conditions of mild, persistent ketonemia, which occur during 
treatment using SGLT2 inhibitors, beta-hydroxybutyric acid is taken up by various organs, including the heart, resulting in oxidation of free fatty acids being displaced. This substrate selection increases the transduction of oxygen consumption into cell metabolism at the mitochondrial level. Furthermore, the hemoconcentration which follows administration of SGLT2 inhibitors increases oxygen release to the tissues, thereby establishing a strong synergy with the metabolic substrate shift. These cell mechanisms may cooperate with observed clinical effects (increased diuresis, reduced blood pressure) to achieve the protective effect observed during the EMPA-REG OUTCOME trial.

Concerning hypoglycaemic agents, it was so far shown that including metformin in case of patients with newly diagnosed diabetes who are concomitantly overweight allowed to reduce the risk of myocardial infarction [20]. However, this effect was only observed in those patients, in whose case there was no necessity to include further hypoglycaemic agents during the trial. In turn, including pioglitazone in patients at high $\mathrm{CV}$ risk reduced the probability of CV complications, but was associated with increased risk of heart failure [21].

Results obtained during the EMPA-REG OUTCOME trial show decreased mortality and occurrence of other complications, at the cost of merely increasing frequency of genital infections - a complication which is easily treatable and which did not cause the need to discontinue the therapy during the trial. The EMPAREG OUTCOME trial is a breakthrough in the treatment of type 2 diabetes, enabling the possibility to reduce mortality of patients with type 2 diabetes.

We await the results of other ongoing trials concerning this class of drugs. These include, among others, DECLARE, a trial of dapagliflozin, CANVAS, a trial of canagliflozin, and VERTIS, a trial of ertugliflozin [22]. They will allow to assess whether the protective effect concerns the entire class of SGLT2 inhibitors or is specific only to empagliflozin.

\section{REFERENCES}

1. Sarwar N, Gao P, Seshasai SR et al. Diabetes mellitus, fasting blood glucose concentration, and risk of vascular disease: a collaborative meta-analysis of 102 prospective studies. Lancet 2010; 375: 2215-22.

2. Di Angelantonio E, Kaptoge S, Wormser D et al. Association of cardiometabolic multimorbidity with mortality. JAMA 2015; 314: $52-60$
3. Gaede P, Lund-Andersen $H$, Parving HH, Pedersen O. Effect of a multifactorial intervention on mortality in type 2 diabetes. N Engl J Med 2008; 358: 580-591.

4. The Action to Control Cardiovascular Risk in Diabetes Study Group. Effects of intensive glucose lowering in type 2 diabetes. $\mathrm{N}$ Engl J Med 2008; 358: 2545-2559.

5. The ADVANCE Collaborative Group. Intensive blood glucose control and vascular outcomes in patients with type 2 diabetes. N Engl J Med 2008; 358: 2560-2572.

6. Duckworth W, Abraira C, Moritz T et al. Glucose control and vascular complications in veterans with type 2 diabetes $\mathrm{N}$ Engl J Med 2009; 360: 129-139.

7. Holman RR, Paul SK, Bethel MA, Matthews DR, Neil HA. 10-Year follow-up of intensive glucose control in type 2 diabetes. $N$ Engl J Med 2008; 359: 1577-1589.

8. Department of Health and Human Services, Food and Drug Administration. Guidance for industry: diabetes mellitus - evaluating cardiovascular risk in new antidiabetic therapies to treat type 2 diabetes (http://www .fda .gov/ downloads/drugs/guidancecomplianceregulatoryinformation/guidances/ ucm071627.pdf.

9. Gallo LA, Wright EM, Vallon V. Probing SGLT2 as a therapeutic target for diabetes: basic physiology and consequences. Diab Vasc Dis Res 2015; 12: 78-89.

10. Bays $\mathrm{H}$. Sodium glucose co-transporter type 2 (SGLT2) inhibitors: targeting the kidney to improve glycemic control in diabetes mellitus. Diabetes Ther 2013, 4: 195-220.

11. Tahrani AA, Barnett AH, Bailey CJ. SGLT inhibitors in management of diabetes. Lancet Diabetes Endocrinol 2013; 2: 140-151.

12. Hasan FM, Alsahli M, Gerich JE. SGLT2 inhibitors in the treatment of type 2 diabetes. Diab Res Clin Pract 2014; 104: 297-322.

13. Wright EM, Hirayama BA, Loo DF. Active sugar transport in health and disease. J Intern Med 2007; 1: 32-43.

14. Han S, Hagan DL, Taylor JR et al. Dapagliflozin, a selective SGLT2 inhibitor, improves glucose homeostasis in normal and diabetic rats. Diabetes 2008; 6: 1723-1729.

15. List JF, Woo V, Morales E, Tang W, Fiedorek FT. Sodium glucose cotransport inhibition with dapagliflozin in type 2 diabetes. Diabetes Care 2009; 4: 650-657.

16. Zinman B, Wanner C, Lachin JM et al.; EMPAREG OUTCOME Investigators. Empagliflozin, cardiovascular outcomes, and mortality in type 2 diabetes. N Engl J Med 2015; 373: 2117-2128.

17. Polskie Towarzystwo Diabetologiczne. Zalecenia kliniczne dotyczące postępowania u chorych na cukrzycę 2016. Stanowisko Polskiego Towarzystwa Diabetologicznego. Diabetologia Kliniczna 2016: 5: Suppl A

18. Inzucchi SE, Zinman B, Wanner C et al. SGLT-2 inhibitors and cardiovascular risk: Proposed pathways and review of ongoing outcome trials. Diabetes \& Vascular Disease Research 2015; 12: 90-100.

19. Ferrannini E, Mark M, Mayoux E. CV Protection in the EMPA-REG OUTCOME Trial: A "Thrifty Substrate" Hypothesis. Diabetes Care DOI: $10.2337 / \mathrm{dc} 16-0330$ (opubl. 11.06.2016).

20. UK Prospective Diabetes Study (UKPDS) Group. Effect of intensive blood-glucose control with metformin on complications in overweight patients with type 2 diabetes (UKPDS 34). Lancet 1998; 352: 854-865.

21. Dormandy JA, Charbonnel B, Eckland DJ et al. Secondary prevention of macrovascular events in patients with type 2 diabetes in the PROactive Study (PROspective pioglitAzone Clinical Trial In macroVascular Events): a randomised controlled trial. Lancet 2005: 366: 1279-1289.

22. www.clinicaltrials.gov 